\title{
Different Teaching Methods: A Panacea for Effective Curriculum Implementation in the Classroom
}

\author{
Theresa Ebiere Dorgu \\ Department of Teacher Education, Faculty of Education, Niger Delta University, Wilberforce Island, Bayelsa State, Nigeria
}

\section{Email address:}

ebiered@yahoo.com (T. E. Dorgu)

\section{To cite this article:}

Theresa Ebiere Dorgu. Different Teaching Methods: A Panacea for Effective Curriculum Implementation in the Classroom. International Journal of Secondary Education. Special Issue: Teaching Methods and Learning Styles in Education. Vol. 3, No. 6-1, 2015 , pp. 77-87. doi: 10.11648/j.ijsedu.s.2015030601.13

\begin{abstract}
The paper focused on the teaching methods as a panacea for effective curriculum implementation in the classroom in Nigeria. Teaching methods denote various strategies that the teacher uses to deliver his/her subject matter to the students in the classroom based on the instructional objectives to bring about learning. Teaching methods aids learning and help to communicate ideas and skills to the students. There are several teaching methods to use in the classrooms, it is left for the teacher to use the ones most appropriate for the lesson. These methods if properly used will enhance teaching and learning and bring about desired changes in the students. While the teacher's task is to ensure that learning is effective, one major way to achieve this is the use of appropriate teaching methods. This paper examines the concept of teaching, the teacher, learning, and discussed various teaching methods that can be used in the classrooms. The paper further discussed curriculum implementation and its implication for teaching methods and proffered the way forward for an effective use of teaching methods for better results in the classroom teaching and learning process.
\end{abstract}

Keywords: Teaching Methods, Curriculum Implementation, Teacher, Classrooms

\section{Introduction}

To educate is to impact knowledge, positive judgment and a well developed wisdom to the learner through a learning process. Formal education is the application of pedagogy, a body of theoretical and applied research relating to teaching and learning. Imparting of knowledge lately comprises a complex mingling of factors as political, social, economic and cultural, due to the fact that the logistics of education are constantly changing, and education presently engages creatively with the transformation of the society, and partakes in it. Therefore, it is necessary that this aspect of modern education be reflected in the models of teaching with its constant evolving needs.

Teaching is a deliberate activity done in a professional manner to bring a positive change on the learner; in order to teach well. Teachers are guided by certain principles of teaching and learning which have great implication for teaching. The role of the teacher is very essential in the effective implementation of the curriculum. The teacher amongst other things must be abreast with the fundamental principles of teaching that will enable him/her to be efficient and productive in the discharge of his/her duties. Teachers challenge the 3 domains of cognitive, affective and the psychomotor domain of learners. The teacher's task is not complete until he/she evaluates to determine if the set objectives have been achieved.

Method of teaching denotes the strategy by which a teacher delivers his/her subject matter to the learners based on some predetermined instructional objectives in order to promote learning in the students. For a teacher to effectively adopt any teaching method, some factors must be considered. The effective implementation of any curriculum depends to a large extent on the availability of various methods of teaching. Thus to teach is to impact knowledge, an attempt to help the learner have a change of attitude and acquire skills through a series of planned activities (Buseri \& Dorgu, 2011).

This paper presents the reader with some methods of teaching and how these methods of teaching can be incorporated within the framework of changing patterns of education. It is hoped that the content of this paper fosters a better understanding of teaching for the teachers and other 
readers.

\subsection{The Concept of Teaching}

Teaching is an attempt to bring about desirable changes in human learning, abilities and behaviour in order to contribute to better living. Teaching helps people to gain the knowledge, skills and attitudes they need to be responsible citizens. It is also a means of passing knowledge to the next generation. Awotua-Efebo (2001) sees teaching as an interaction between a teacher and a student under the teacher's responsibility, in order to bring about the expected change in the students behaviour. According to Gagne \& Briggs, 1989 in Awotua-Efebo (2001), the purpose of teaching, are to help students to

- Acquire, retain and be able to use knowledge

- Understand, analyse, synthesize and evaluate skills

- Establish habits and

- Develop attitudes

Omieibi-Davies (2011) sees the changes in behaviour that occurs as a result of teaching as follows:

a. An increased store of useful information and the understanding of basic principles in the subject matter. b. An acquisition of psychomotor skills, abilities and habits.

c. Possession of desirable attitudes and ideas, such as developing satisfaction about learning outcomes.

\subsection{Components of Teaching}

In order to come up with an effective teaching approach, three major components of teaching have been identified namely:-

1. Preparation - Here the teacher plans the lessons he/she intends to teach including all the activities needed to put the lesson together.

2. Execution - Here the teacher is involved in communicating the lesson to the students as prepared in the lesson notes using the designed teaching model/strategies. The classroom management is also involved here.

3. Evaluation - Here the teacher does all it takes to ensure that the lesson is effective considering the teaching model used for a particular class. Students are evaluated here through tests, and other quizzes, etc
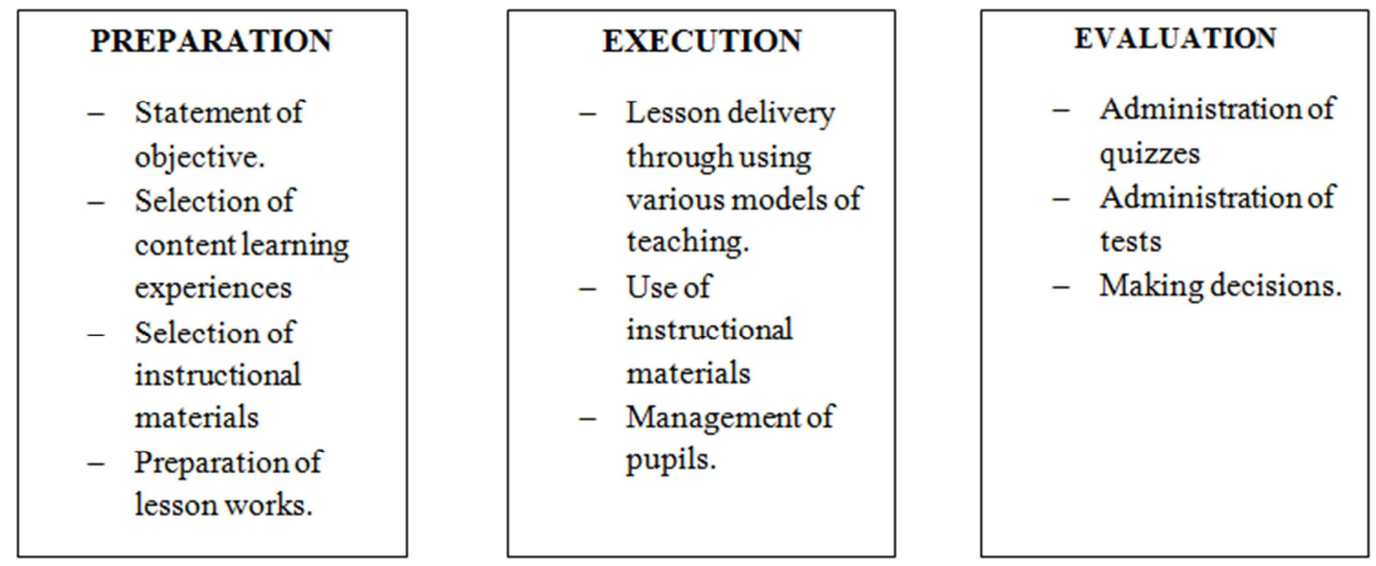

Fig. 1. Components of Effective Teaching-Awotua-Efebo 2001.

\subsection{Teaching Principles}

In order to carry out an effective teaching task below is a list of helpful guide for a successful teaching.

1. Planned teaching results in more learning. The teacher must be clear in his/her mind right from the start on what he/she intend to do. Teachers are encouraged to plan their lessons extensively; such defined goals helps the teacher to determine the methodology appropriate to the subject matter to aid teaching and learning.

2. Teachers should be able to guide students effectively to achieve the objectives of lessons taught.

3. Students tend to achieve in ways they are tested, teachers are encouraged to test students in different ways to enhance their achievement rates in various domains.

4. Students learn from one another. Encourage students to work in groups while solving problems as this goes a long way to enhance learning.

\subsection{The Teacher}

A teacher is expected to have a total commitment in giving the children the type of education that trains them to growth and development. A teacher is a person who is qualified in every way as a professional teacher to teach in schools especially in his/her area of specialization. A teacher's personality type should be divergent, enduring and stable enough to help learners solve their problems. No educational system can be stronger than the caliber of the teaching staff. In recognition of this fact, the Federal Republic of Nigeria National Policy on Education (2004) stated, "All teachers in our educational institutions, from pre-primary o university, will be professionally trained. The teacher is the sole implementer of the curriculum in the classroom. The main focus of the implementation of the curriculum is the learner, while the most important person in curriculum implementation is the teacher. (Obasi, Adaobi \& Ajeka, 2007). 
The teacher is the prime mover of the educational system. Aghanta (1991) conceptualizes that as an input operator into the educational system, the teacher plays a major role in the conversion of raw materials particularly students into finished products e.g. graduates.

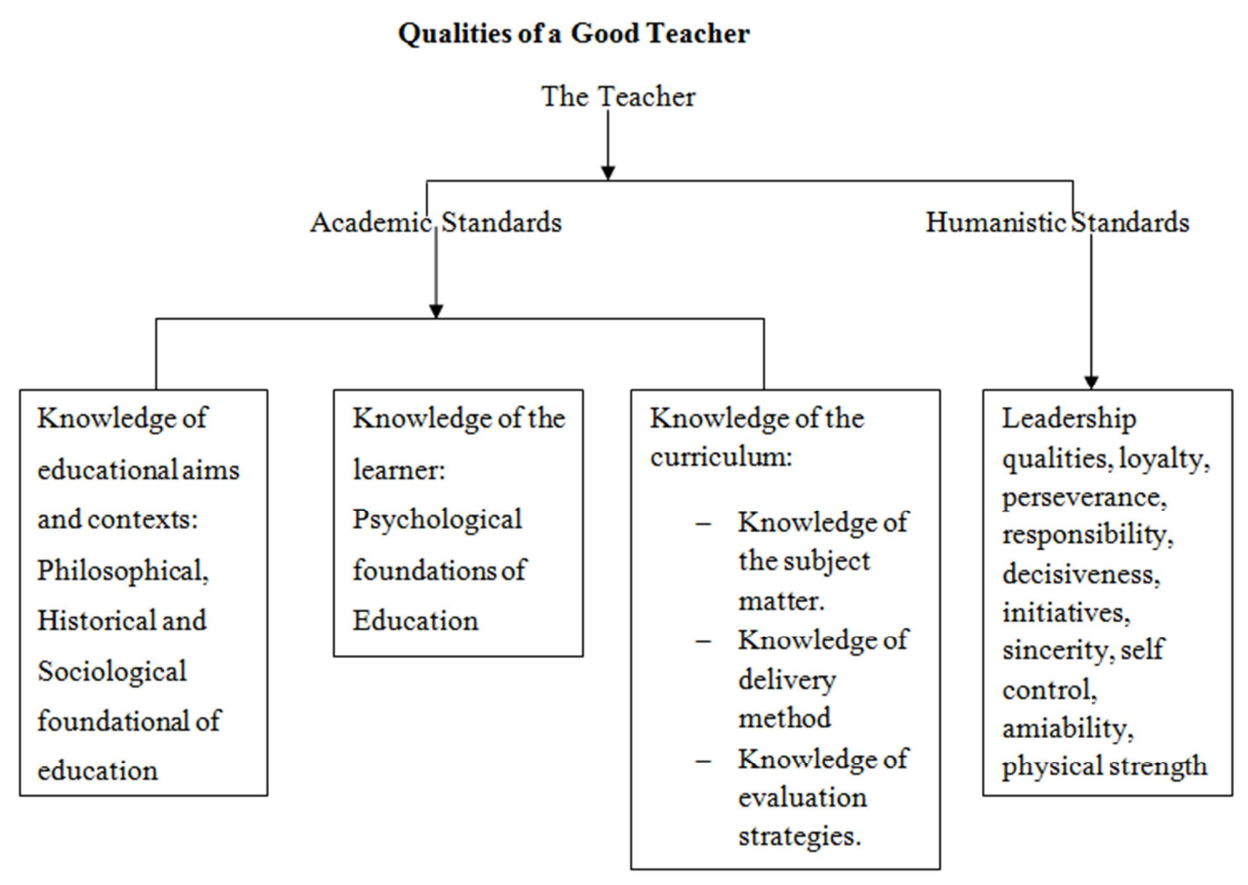

Fig. 2. Qualities of a Good Teacher Vikoo (2003).

The Characteristics of a good teacher can be grouped under two broad standards Academics of Humanistic standards

Academic Standards - A teacher due to his training is grounded in his area of specialization. Vikoo (2003) opines that the knowledge required of a teacher can be condensed into three main types namely.

1. Knowledge of educational aims and contexts. The aims and objectives of education vary from societies based on the problems and needs of the society. The teacher needs to be grounded in the historical, philosophical, sociological and other issues the society is experiencing and how education can be used in solving them.

2. Knowledge and characteristics of the learner: A good teacher should understand how children learn and develop. He/she should be able to provide learning opportunities that supports their intellectual, social and personal development. Education revolves around the learner; a learner who has acquired a sound education should be able to contribute to the solutions of problems in society.

3. Knowledge of curriculum: The teacher here should understand and have the knowledge of the subject matter, delivery methods and knowledge of evaluation methods.

The Humanistic standards of a teacher deals with his/her personality traits, such as: his/her sense of responsibility, amiability, initiative, sincerity, self-control, loyalty, physical strength, leadership qualities and be good personality, decisiveness, likes fun and a sense of humour, punctual, co-operates with colleagues and be committed to self improvement amongst others. All these will help the teacher to succeed in the varied task he/she must perform.

Finally, success in the discharge of the duty of a teacher depends to a large extent on the degree to which teachers possess the necessary cognitive, affective \& psychomotor skills. Therefore, the teacher should have the appropriate knowledge, attitude \& physical skills to carry out whatever activities he/she is expected to engage in, to help learners acquire desired knowledge and skills to bring about changes.

\section{What is Learning}

Learning has been defined in various ways based on various theories explaining the process of learning. Learning involves changes in the behaviour patterns of an individual. Simply put, learning is the process of acquiring knowledge or skills and attitudes. This can be illustrated thus:

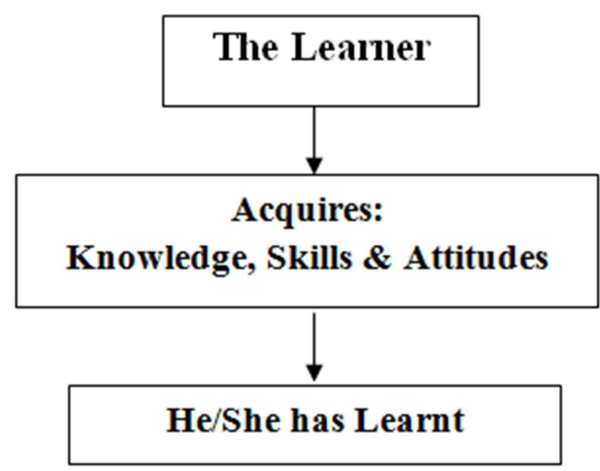

Fig. 3. Definition of Learning. 
Some learning principles that can be used to facilitate teaching of learning in the classroom are:-

1. Students learn best by being actively involved in learning activities.

2. Positive or reward reinforcement is more likely to result in students' learning than negative reinforcement.

3. A situation which offers fresh and stimulating experiences is a kind of reward that enhances learning.

4. Meaningful material is easiest learnt and best retained

5. Learning is increased when provided in a rich and varied environment.

6. Detail must be placed into a structured pattern or it is forgotten.

7. Learning is enhanced by a wide variety of experiences which are organized around purposes accepted by the students.

8. Learning is transferred to the extent the learner sees possibilities for transfer and has opportunities to apply his knowledge. (Gbamaja, 1991).

It is important to understand the primary objective of teaching which is to bring about good education. Prospective teachers are encouraged to know the operation and approaches to learning in order to develop better teaching methodologies. In using these teaching methods, teachers should consider every learner's unique attribute. Teaching calls for an active participation of the learner, thus for teaching \& learning to be effective, it has to ensure a joint teacher-learner-class activity based on variety of methods which creates room for effective and efficient mastery of the subject matter on the part of the learner.

\subsection{Teaching Methods}

Simply put, teaching method is any teaching maneuver that can be used to facilitate students learning and satisfaction. Different teaching methods may elicit different types of changes in learning outcomes. Teaching methods are many and varied and could be used in different ways, considering among others the age of the learners, body configuration or physique of learners, (able or disabled learners). Academic ability/intelligence of the learners, number of learners and of course the type of curriculum discipline which recognizes the fact that certain teaching methods are much more suitable to some disciplines than others.

Vikoo (2003) is discussing types of teaching methods explained that teaching methods could be presented under three main categories:

- Cognitive development methods

- Affective development methods

- Psychomotor development methods

1. Cognitive Development Methods

Here, if the focus of the instructional objectives is to develop intellectual skills in learners, then the cognitive development methods of teaching are recommended. This method helps learners to comprehend, analyse, synthesize and evaluate information. It helps learners develop good cognitive abilities. Though the cognitive development methods are essentially didactic. Some of the teaching methods in this category includes:

- Discussion Method

- Questioning/Socratic Method

- Team Teaching Method

- Talk Chalk/Recitation Method

- Field Trip/Escortion Method

- Team Teaching Method

2. Affective Development Method:

This domain includes objectives which describe changes in interest, attitudes and values. It further deals with the development of appreciation and adequate adjustment. Education has a lot to give the learner in order to assist $\mathrm{him} /$ her develop in these areas, hence teachers are encouraged to include learning experiences that are worthwhile, teach in ways that arouse interest and develop proper attitude in learners. This mode of teaching are basically Philetic, here students feelings or opinion are aroused. Some teaching methods under this category includes:

- Modelling Method

- Simulation Method

- Dramatic Method

- Simulation Games

- Role-Playing Method

3. Psychomotor Development Methods

These are activity based methods of teaching that aim at motor skills development in learners. This method requires that learners are able to illustrate, demonstrate, or perform certain skills using their manual dexterity. It is a heuristic method of teaching that involves inquiry and discovery methods of teaching. It is a more student activity based method. This method includes:

- Inquiry Method

- Discovery Method

- Process Approach Method

- Demonstration Method

- Laboratory/Experimentation Method

- Programmed Learning Method

- Dalton Plan/Assignment Method

- Project Method

- Microteaching Method

- Mastery Learning

Over the century, a great number of teaching methods have been developed, modified and even combined. Below is a list of some teaching methods that can be used to facilitate learning generally. 


\section{Adapted From Cruickshank, D.R., Bairer, D. \& Metcalf, K. "The Act of Teaching". 1995 pg. 197}

The Wheel of Instructional Choice showing Various Teaching Methods

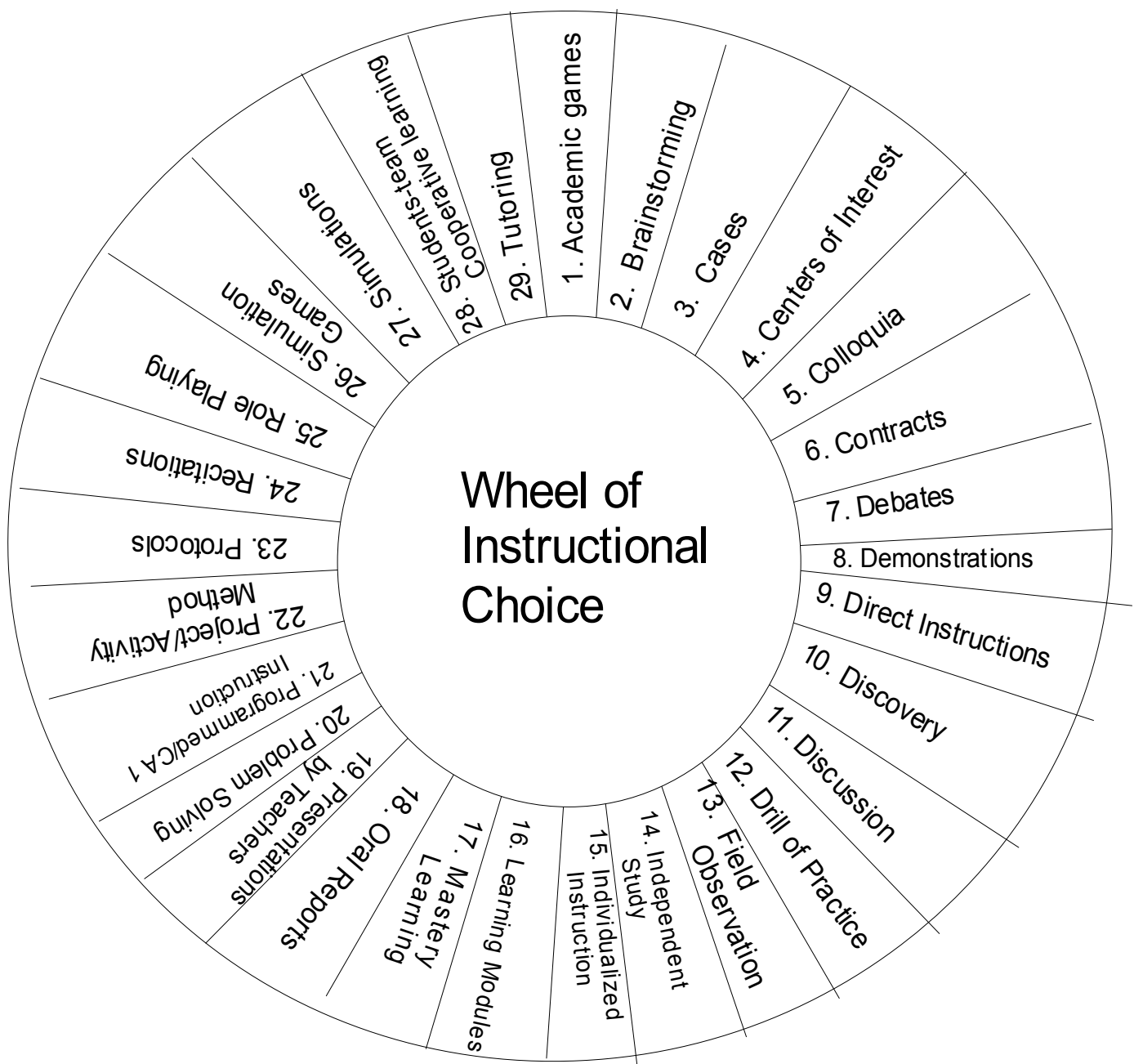

Fig. 4. Wheel of Instructional Choice showing various Teaching Methods.

As already mentioned, there are several methods of teaching; the following methods will be discussed in this paper:

1. Discussion method

2. Questioning method

3. Role Playing Method

4. Stimulation Method

5. Demonstration Method

6. Inquiry/Discovery Method

\subsection{Discussion Methods}

Discussion is usually at a higher cognitive level and it develops critical thinking. Student's participation is necessary for a successful classroom discussion. It is a student centered teaching technique but requires careful planning by the teacher to guide discussion. Successful discussions are guided by specific teaching goals. It involves a process of free guided 
discussion and expression of views and ideas on a given topic, question or problem by the teacher. In the students attempt to solve the problem or answer the question, students pair up in smaller groups for about 5 minutes or more, discuss the issue on ground and then they are brought back for a full group discussion. Various students are able to participate and are exposed to other student's ideas. In small group students can discuss a complex issue and when they are brought back to the larger groups, these students can discuss their reactions, share ideas and build on each other's suggestions. This method encourages student's participation, develops critical thinking, develops student's ability to communicate, and problem solving skills. It allows all to participate.

Trouble Shooting: Atimes, in the process of critical discussion, it turns out into emotional charged unproductive debates, here the teacher should get other students involved to identify the issue of conflict and encourage them to analyse the discussion with less emotional charge. Discussion method can be tedious to co-ordinate and not practical with a lot of students at once.

Finally, discussions are characterized by multiple interactions, with the teacher as the facilitator. Discussions are basically small groups in nature and these groups vary in size and composition. Participant interactions are encouraged to be arranged face-to-face.

\subsection{Questioning Method}

Questioning method of teaching aids learners in connecting concepts, increasing awareness, encouraging creative and imaginative thought, making inferences etc. Questioning generally helps learners to explore deeper level of thinking, knowing and understanding. Questioning, though it is more of a technique than a method of teaching, it is used during various methods of teaching. Questioning aids in sensitizing the inquisitive mind of the learner. This method is credited to Socrates, a Greek Philosopher. Questioning methods may be used for the following purposes:

1. To arouse interest \& curiosity: At the beginning of a lesson, questions can be used to secure interest, and focus the attention of the group on the subject.

2. To stimulate discussion: Question that are thought-provoking can get the group to start reactions.

3. To channel thinking: By skillful questioning, the teacher can steer the group to the objective he has established, keep them on the right track and guide their thinking. The teacher can also help the group to move from the known to the unknown by a series of well-prepared questions.

4. To determine how well the group understand the material: By the response given to a question, the teacher can determine if the group has absorbed what is being presented, and provides opportunity to correct any misconceptions or to elaborate on points.

5. To get the attention of an individual: To help a timid person to express his or her thoughts (Achuonye \& Ajoku, 2003).

There are five basic types of questions namely:
- Factual: These require straight forward answers based on obvious facts or awareness. Answers are either right or wrong-yes or no.

- Convergent - Answers to questions of this nature are usually within a finite range of acceptable accuracy. They allow for only one right response; they are questions about concrete facts.

- Divergent: These questions allow for many right responses. These questions give students the room to explore various avenues, creates alternative answers. Correct answers here could be based on logical projections or imagination. Questions here deal with opinions, hypotheses \& evaluation and they predict different outcomes.

- Evaluative: Evaluative questions are open-ended \& more difficult to answer, because some criteria must be established for making any judgment. Basically, evaluative questions require students to make judgments on something. Responses to these questions are limited to a number of choices.

- Combination: These are questions that blend and can be combined as a question example.

i. What are the differences and similarities between the death of late General Sanni Abacha when compared to that of General Muritala Mohammed (all of Nigeria).

\subsection{Characteristics of Good Questions}

1. Good questions should be clear, brief, concise and direct to the point. They should be free from ambiguity.

2. Good questions should be thought-provoking.

3. They should suit the age, abilities, interest and characteristics of the particular learners or audience at hand. (Gbamanja, 1991)

\subsection{Guidelines for Questioning}

- Ask clear questions

- Call students by their names

- Ask questions that match lesson objectives.

- Distribute questions fairly among students

- Frame questions in ways that one act leads logically to the next.

- Avoid too much questions within a lesson.

- Give students time to think after a question is asked

- Teacher gives a final comment to the answer

\subsection{Role Playing}

This method of teaching can be used for solving real life situational problems. The technique of role lay develops practical professional skills and functioning knowledge. It enables students in the classroom to act as stakeholders in an imagined scene. In a play role, the teacher selects an event that illuminates the topic of study and students are assigned roles, which will be played out, the role play will be concluded, with a reflection stage that reinforces the concepts introduced by the role play. This method gives students the opportunity to 
explore together their feelings, attitudes, values and problem solving strategies. Role play also creates a stimulating environment that brings reality to life and intensify learners understanding of the event being played. This method intensifies and accelerates learning, it can be described as a hands-on approach to learning \& students learn through active involvement in role-play. The problem with role playing method amongst others is that directing a role playing is complex. Also, some students may be too self-conscious and may not be able to play the role for other students to observe.

\subsection{Games/Simulation Method}

This method entails a real life activity in a simple manner that communicates the idea to the learners. Example, If the "use of money" is the topic in class; the teacher gets two students to act a trader and a customer scene, where the customer buys the items from the trader with the money, in this scene, the use of money is depicted in real life situation. This kind of simulation is better than mere verbal description.

Omieibi-David (2001) conceptualizes simulations as an imitation of real life situations that requires participants to play a role that involves them in interaction with other people or with elements of the environment concerned.

The use of stimulation methods in classroom situations is devised to help students learn how things operate in reality. Students are encouraged to act out the same roles and make decisions likened to real life situations. Therefore, simulation helps students to practice and understand adult roles and also develop the skills necessary for a successful adult life. Simulation and games are used at all levels of education and creates both intrinsic and extrinsic motivation in the learner. While simulation methods present the students realities of life in concrete and simple forms, they are innovative and a welcome change in the learning experiences as compared to the routine classroom learning. Simulation problems shooting areas lies in the fact that it is time consuming, very expensive, especially in an attempt to purchase a reasonable number for class use. It also requires great classroom management.

\subsection{Demonstration Method}

A demonstration involves showing, doing or telling the students the point of emphasis. It is mostly used as a technique within a method of teaching and a times as a method of teaching itself. Here the role of the teacher is to illustrate how to do something or illustrate a principle first by explaining the nature of the act verbally, followed by demonstrating the act in a systematic manner and later the students repeats the act. Here students are involved in dong things that will influence their behaviour patterns, through demonstrations, students are exposed to physical materials that will illustrate some meaning to their cognitive framework. Direct experiences like this go a long way to enrich learning. Demonstration is useful mostly in imparting psychomotor skills and lessons that require practical knowledge. The gains of using demonstration method in teaching lies in the fact that it bridges the gap between theory and practice, enables learners to become good observers and generate their interest; students see immediate progress as a result of a correct effort and it enables the teacher to teach manipulative and operational skills. The problems encountered in this method amongst others include the fact that students loose interest and confidence when they fail to repeat accurately; creativity and originality by students are hindered as students try to do it exactly the same way as their teacher did it and students have a limited opportunity to be familiar with learning materials.

\subsection{Inquiry/Discovery Method}

This is a teaching learning situation whereby students are given the opportunity to discover and find out things for themselves. Inquiry/discovery methods have been known to provide meaningful learning to students when compared to other methods. This method is rooted in the heuristic teaching activity and problem solving; these are basically the major ingredients of modern science. It is a learner centered method, whereby the learner discovers \& explores some problem solving experiences with a view to draw conclusions from data gathered through the process of observing, predicting, measuring and formulating relevant questions. Learning acquired through inquiry/discovery method is mostly accepted as more meaningful and authentic than learning imposed by external forces. This method can be used with students at any acadmic level though more effective with students at the secondary and tertiary levels.

Two types of discovery methods can be used by the teacher namely the structured method and the open discovery method.

Structured Method: Here the teacher gives a clear set of instructions that learners are to follow to discover a fact, idea or skill for themselves.

Open Discovery Method: The teacher in this method presents a problem, gives some questions and directions that requires learners to find answers to. Here, the teacher gives the learner the freedom to explore different perspectives, views, possibilities, and solutions to the problem.

There are no stereo type answers as the learners arrive at different solutions to a problem, especially in the case of the open discovery method. In both situations, they are expected to find the solution within a specific time frame.

The gains of inquiry/discovery methods includes

- It demonstrates students proficiency

- It encourages curiosity

- It encourages students to develop coding system which helps them to make connection among objects and phenomena.

- Fosters intuitive thinking in the classroom

- Develops good communication skills as science requires distinct communication for accurate sharing of methods and findings and

- Finally, students become independent thinkers.

Below are some problems experienced in using the inquiry/discovery method of teaching.

- It is not cost effective

- It requires a lot of planning before it can be implemented

- It is time consuming 
- Unsuccessful attempts at arriving at needed solution may have negative impact on students.

\section{Criteria for Selecting Teaching Methods}

In selecting teaching method, the teacher's analytical ability comes to play considering the situation at hand. There are some factors that will guide the teacher's choice of method to use in teaching a particular lesson; such factors include:

- The subject matter

- Instructional objectives

- The learner

- The teacher

- The time

- Instructional materials

- The environment

These factors are discussed below:

\subsection{The Subject Matter}

The content of a subject determines what method to be used to achieve effectiveness in the teaching and learning process. Subjects could be science or arts oriented, and as such, they definitely require different teaching methods that suit such disciplines. Science subjects are better taught with the inquiry or discovery methods while the lecture method can be used in some art subjects depending in the content of the subject.

\subsection{Instructional Objectives}

The instructional objectives a teacher intends to achieve at the end of a lesson, determines the choice of teaching method to use in teaching the subject. Example from the objectives of a lesson, the teacher will know if the lesson intends to acquire new skills or illicit an emotional or aesthetic reaction from the students; knowledge of these will go a long way in determining which teaching method to use.

\subsection{The Learner}

The learner is the pivot of teaching a teacher will have to know the student's prior knowledge. The age, ability and the number of learners needs to be considered in some teaching method suitable for students within a given age group; students with different physical and mental abilities/disabilities, interest, students at the primary, secondary or higher institutions. Example- a method used with the physically challenged cannot be used with the normal students.

\subsection{The Teacher}

The teacher is the person that has to initiate the particular teaching method or methods he/she intends to use in a given lesson. He/she should be familiar with such methods and be prepared in every way. The teacher should endeavour to vary the methods he/she uses in teaching and should not be known to using a particular method always.

\subsection{Time}

The time allotted to a subject on the school time-table should be considered when determining the choice of teaching method. Methods like role-playing, simulations can be done within double periods. When there is little time to cover large scheme of work, then, the lecture method can be used, but the learners must be considered in every way.

\subsection{Instructional Materials}

These go a long way to determine what teaching methods to use in a given lesson e.g. a teacher that wants to teach a practical class in biology needs an equipped biology laboratory to demonstrate effectively, but where there is none; will end up with just a lecture method which does not completely suit that topic.

\subsection{The Classroom Environment}

Classroom environment set a tone for learning and causes learners to behave in certain ways. It is important to consider the classroom environment in selecting an appropriate teaching method for a lesson. The space available in a class, ventilation, illumination and other teaching devices in a classroom, etc all these affects the choice of teaching methods to be used.

A Programme Chart for Selecting Appropriate Teaching Method

(Ellington \& Earl, 1998) 
$\underline{\text { Stage } 1}$

\section{$\underline{\text { Stage } 2}$}

\section{$\underline{\text { Stage } 3}$}

$\underline{\text { Stages } 4}$

$\underline{\text { Stage } 5}$

$\underline{\text { Stage } 6}$

$\underline{\text { Stage } 7}$

\section{Are you clear as to what your instructional objectives are? If not clarify them now}

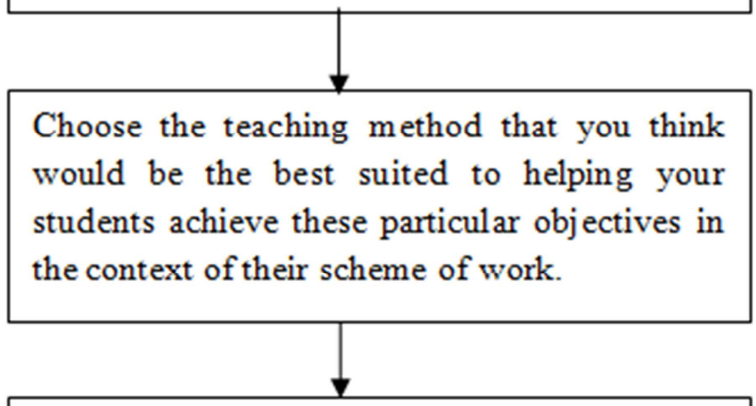

Will your students be comfortable with the method (s) you have chosen?

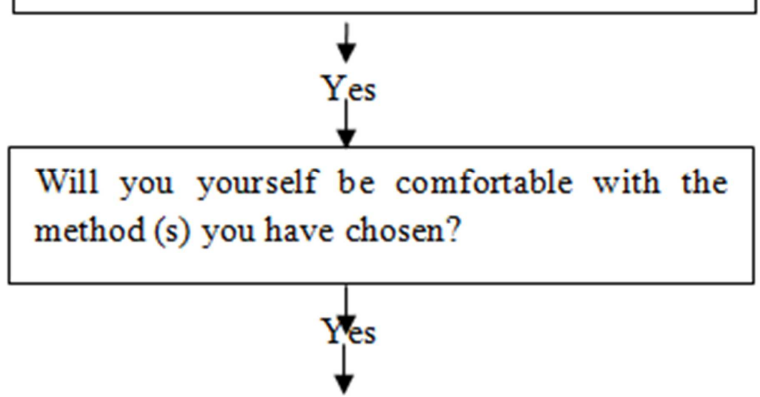

Will your chosen method (s) be practical?

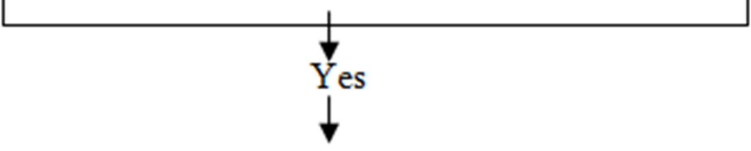

Will you be allowed to use the method (s) you have chosen?

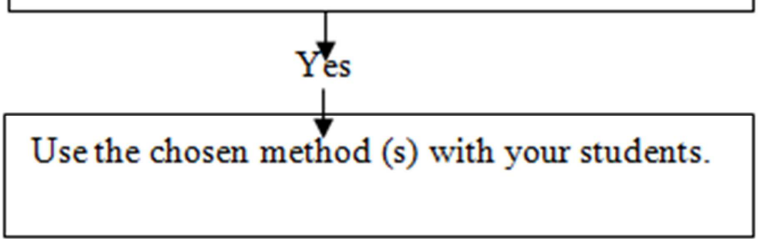

Fig. 5. A Chat for Selection of Appropriate Teaching Methods.

Curriculum Implementation \& Its Implication for Teaching Methods

Curriculum is the planned and guided learning experiences and intended learning outcomes formulated through systematic reconstruction of knowledge and experiences for learners under the auspices of a school. (Tanner and Tanner (1975). Curriculum to Offorma (2005) is a structural series of learning experiences intended for the education of the learners under the guidance of the teacher. Nnachi (2009) conceptualizes curriculum as a programme of education made as a guide to the teacher and learner in respect of procedure, content an context of the course of study under the guidance of the school for effective teaching and learning. In summary of all the definitions above, curriculum is the totality of the systematically planned experiences which the school offers to the learners.

The ability to put curriculum content and other instructional guidelines into practice inside the classroom can be referred to as curriculum implementation. Oforma (2005) stated that curriculum implementation is the transmission of the planned curriculum into the operational curriculum. On the other hand, Ivowi (2004) viewed curriculum implementation as the process of putting all that have been planned as a curriculum process into practice in the classroom through the combined efforts of the teacher, learner, school administrator as well as the interaction with the physical facilities, instructional materials, psychological and social environment.

Therefore, curriculum implementation is the sole concern of the teacher, and the interaction of learners and other education administrators geared towards achieving the 
objectives of education. Teachers carry out the task of providing learning experiences by providing instruction; these instructions can be achieved through the use of various teaching methods that are made available. Fundamentally, teaching is concerned with the attainment of maximum beneficiary learning for the learner. The teacher's major task among others is to ensure that learning is effective and efficient. Teaching methods known as patterns of interaction between the learners and the teachers are intended to lead to a change in the learner's behaviour.

There are a variety of teaching methods, and it is through the use of such teaching methods that teachers are able to implement the school curriculum. In situations where teachers fail to use appropriate teaching methods, a good curriculum plan could turn out to be damaged. The main purpose of curriculum implementation is to translate the ideas into a workable blueprint, and this can be achieved basically by using appropriate teaching methods in class. The secondary school curriculum as planned learning experiences provided to assist the learners in attaining the designated learning outcomes can be attained by the use of effective teaching methods. The teacher through his teaching methods makes direct use of the curriculum, thereby implementing it. The teacher uses the appropriate teaching methods and resources to achieve learning. Whenever a teacher is teaching a lesson through the means of various teaching methods, he is implementing the curriculum.

\subsection{The Way Forward}

The following suggestions are made for effective use of teaching methods in the teaching and learning process.

1. Teachers should know the nature of the subject matter to be taught and be conversant with it to enable him/her determine the most suitable teaching method/methods to use in a given lesson.

2. The instructional objectives a teacher intends to achieve by the end of the lesson determines to an extent the type of teaching methods. Teachers should try to match the instructional objectives to suit the teaching methods to be chosen for a lesson.

3. The teacher must be very familiar with the type of teaching methods he/she wants to use at any given time; and must ensure it is most appropriate for the success of the lesson.

4. The teacher must consider the age, interest, etc of the learner and ensures the right teaching methods and materials that will suit the learners are in place.

5. In choosing appropriate teaching methods, the teacher is encouraged to consider the time to be used for a lesson, as this will go a long way to determine also the type of teaching methods to use.

6. The teacher should put into consideration the population of the class, the environment and the size of the class. This will help to determine a most suitable teaching method to use for a lesson and make it worthwhile.

\section{Conclusion}

The teacher is a vital factor in the success of an educational system in a nation. Teaching is an attempt to bring about desirable changes in human learning, abilities and behaviour. Effective implementation of the curriculum is dependant in the effective use of appropriate teaching methods in the classroom. Teaching methods are used to facilitate students learning and satisfaction. A variety of the use of teaching methods is a must for teachers if learning is to be effective and efficient. There is need for a good teacher to be multi-talented in other to be conversant with the use of various teaching methods in the teaching and learning process. The teacher is a vital factor in the success of an educational system of a nation; therefore, teachers should be familiar with the principles underlying the choice of teaching methods. A combination of teaching methods is encouraged for effective teaching.

\section{References}

[1] Achionye, K.A and Ajoku, L.I. (2003). Foundations of curriculum development and implementation. Port -Harcourt: Pearl Publishers.

[2] Aghanta, J.A. (1991). Teacher effectiveness in the Nigerian educational system. Edited by Emenogu, B.C. and Okoro, O.V.N. Onitsha: Orient Publishers Ltd.

[3] Awotua-Efebo, E.B. (2001). Effective teaching: principles and practice. Port-Harcourt: Paragraphics.

[4] Buseri, J.C. and Dorgu, T.E. (2011). The relevance of instructional materials for effective Curriculum delivery $\mathrm{n}$ Nigeria. Journal of issues in professional Teacher Education (JTIPTE). 2 (2) P 9.

[5] Cruickshank, D.R., Bainer, D. and Metcalf, K. (1995). The act of teaching. U.SA: Mcgraw- Hill Inc.

[6] Ellington, H. and Earl, S.C. (1998). Facilitating student learning: a practical guide for tertiary- level teachers. London: Kongan Press.

[7] Federal Republic of Nigeria (2004). National Policy on education. Lagos: NERDC Press.

[8] Gbamanja, S.P.T. (1991). Essentials of curriculum and instruction: theory and practice. Port-Harcourt: Pam Unique Publishers.

[9] Ivowi, U.M.O. (2004). Curriculum implementation and school administration in A.O.R. Noah, D.O. Shonibare, A.A. Ojo .T. and Olajuwon, T. (eds). Curriculum implementation and professionalizing teaching in Nigeria, Lagos: Central Education Services.

[10] Nnachi, R.O. (2009). Curriculum implementation at the tertiary level of Nigerian education: curriculum theory and practice. Abuja: CON Publishers.

[11] Obasi, E. Adaobi, .A. \& Ajeka, P.I. (2007) Implementation of social studies curriculum in the junior secondary schools in Owerri educational zone. Journal of Curriculum And Instruction. 6 (3) 1-14 
[12] Offorma, G.C. (2005). Curriculum implementation for functionality. In Oraifor, S.O. Edozie, G.C and Eze, D.N. (Eds). Curriculum issues in contemporary education (pp. 107-203). Benin-City: Da-Silva Press.

[13] Omiebi-Davids, .I. (2011). Skills in effective teaching. Port-Harcourt: Minson Publishers Ltd.
[14] Tanner, D. and Tanner, L. (1975). Curriculum development: theory into practice. New York: Macmillian Co. Inc.

[15] Vikoo, B. (2003). Learning theories and instructional process. Owerri. Springfield Publishers Ltd. 